\title{
Relation Between Levels of Leptine and Metabolic Parameters in Children and Adolescents
}

\author{
Omar Pérez-Álvarez ${ }^{1}$, Edgar Navarro-Lechuga ${ }^{2}$, María del Pilar Garavito-Galofre ${ }^{2} \&$ Eduardo Navarro-Jiménez ${ }^{3}$ \\ ${ }^{1}$ Clínica General del Norte, Barranquilla, Colombia \\ ${ }^{2}$ Departamento de salud pública, Facultad de ciencias de la salud, Universidad del Norte, Barranquilla, Colombia \\ ${ }^{3}$ Programa de medicina, Facultad de ciencias de la salud, Universidad Simón Bolívar, Barranquilla, Colombia \\ Correspondence: Omar Pérez Álvarez, Cl. 70 \#48 - 35. Barranquilla, Colombia. Tel: 57-300-811-4339. E-mail: \\ omperal@hotmail.com
}

Received: August 12, 2018 Accepted: September 29, 2018 Online Published: October 24, 2018

doi:10.5539/ghhs.v10n11p161 URL: https://doi.org/10.5539/gjhs.v10n11p161

\begin{abstract}
Objective: To determine the relationship between leptin levels and metabolic parameters in children and adolescents.

Methods: Descriptive cross-sectional study. Laboratory biochemical values and anthropometric parameters were determined. Univariate analysis was performed with measurements of frequencies and percentages and bivariate analysis through statistical significance tests $(\mathrm{p}<0.05)$. In case of multiple comparisons, the Bonferroni correction was made.

Results: There were higher levels of leptin to higher adipose tissue, while in the metabolic parameters a relationship was observed between high levels of glycemia and leptin independent of the variables gender, age group and nutritional status. There was no clear relationship between high levels of leptin and those of the lipid profile.

Conclusions: There was a relationship between leptin concentrations and nutritional status and in the relationship of leptin with the metabolic parameters studied, there was an association with glycemia, while this association was not clear with the lipid profile.
\end{abstract}

Keywords: pediatric obesity, leptin, glycemia, adipose tissue

\section{Introduction}

According to the World Health Organization (WHO), obesity causes 2.8 million deaths a year worldwide and represents the fifth cause of death worldwide. It is a multicausal disease, which is related to biological, sociocultural and psychological factors. Given its magnitude and importance it is considered in Colombia and throughout the world as one of the biggest health problems and that leads to multiple complications. During the last decades, the prevalence of overweight and obesity in children around the world came in great increase.

Excess weight, which in childhood is mainly due to the accumulation of fat, is a risk factor for obesity in adulthood and all its associated chronic diseases (such as high blood pressure, diabetes and dyslipidemias). But this increase in body fat and early ages is also associated with deteriorating health in childhood, including an increased risk of hypertension, insulin resistance, liver disease, orthopedic and psychosocial disorders (Sánchez Echenique, 2012).

Worldwide, the population has become more obese in the last 4 decades, from obese men from $3.2 \%$ to $10.8 \%$ and women from $6.4 \%$ to $14.9 \%$, it is considered that there are currently 2 billion people in the world with overweight and obesity, of which 700 million are obese (Organización Mundial de la Salud, 2014).

The prevalence of overweight and obese children continues to increase in most countries, the World Health Organization (WHO) considers it as one of the main public health problems in the world and also involves all socioeconomic strata. Also, obesity in children and adolescents is an important risk factor for obesity in adulthood, also relating the excess of adipose tissue in children and adolescents, with metabolic disorders such as: dyslipidemias, glucose intolerance, hyperinsulinemia and hypertension, which represent a set of factors that become as important risk factors for morbidity and mortality due to cardiovascular disease in adult life (Organización Mundial de la Salud, 2014). 
Overweight and obesity are characterized by an increase in adipose tissue which, in addition to being an energy storage organ, also synthesizes hormones, which control important metabolic functions, these hormones are known as adipokines, in over 50 members have been described. When a person becomes obese, adipose tissue alters its functions, decreasing or increasing the production of their adipokines, which leads to metabolic alterations and the activation of mechanisms of inflammation, which will favoring the onset of insulin resistance, dyslipidemias, increased blood pressure, all leading to an increased risk for early cardiovascular disease and diabetes (Martos-Moreno, Kopchick, \& Argente, 2013; Martos-Moreno, Barrios, Chowen, \& Argente, 2013).

Among the most studied adipokines are leptin which is altered with the increase of adipose tissue present in overweight and obesity, and can be considered as an early marker in overweight and obesity in children and adolescents, and a risk signal for metabolic disorders such as insulin resistance, diabetes and dyslipidemia (Martos-Moreno et al., 2013; Martos-Moreno et al., 2013).

The biological hypothesis indicates a relationship of leptin with obesity and this in turn has been associated with diabetes in animal models of obesity (Irecta Najera \& Álvarez Gordillo, 2016).

In multiple studies, plasma leptin levels have been correlated with diseases such as essential hypertension, obesity and insulin resistance and diabetes and metabolic disorders with increased triglycerides and decreased high-density lipoprotein (Irecta Najera \& Álvarez Gordillo, 2016).

Since its discovery, the most studied role of leptin is that of regulating body weight. From these studies it is inferred that leptin inhibits the orexigenic pathway and stimulates the anorexigenic: and the antilipolytic and lipogenic effects of insulin, other studies have shown the powerful stimulating effect of leptin on the growth, proliferation and migration of the endothelial cells. Although leptin is a signal that reduces appetite, obese people have a high concentration of circulating leptin; These people are resistant to leptin. thus, obesity develops when the person ingests more energy than they use during the day, and this excess of food is not triggered by hunger signals, extending despite the anti-appetite signals of leptin (Irecta Najera \& Álvarez Gordillo, 2016).

In humans, leptin levels correlate with fat mass and body weight, both in normal and obese patients. In the latter, the highest levels of leptin fluctuate in short periods of fasting or refeeding, without any significant change in the total body fat content, which suggests that leptin acts as a sensitive regulator thereof, so that lipid metabolism could be closely associated with the regulation of leptin (Gomez, 2013; Hernández-Arteaga, Rosero-Galindo, \& Montenegro-Coral, 2015).

Obesity and overweight are characterized by excessive storage of adipose tissue. Adipocytes are considered endocrine glands that secrete a variety of active protein hormones such as leptin, which can participate in the genesis of various diseases in patients with overweight and obesity, so they have been postulated as a risk biomarker for patients Overweight and obese from an early age (Skurk, Alberti-Huber, Herder, \& Hauner, 2007; Zhang, Zitsman, Hou, Fennoy, Guo, Feinberg, \& Leibel, 2014).

In a study in Spain, in prepubertal children, leptin correlated significantly with BMI $(r=.57, \mathrm{p}<0.001)$ and triglycerides $(\mathrm{r}=.31, \mathrm{p}<0.007)(2)$. $\mathrm{n}$ a study conducted in Asia, China, it was found in Chinese adolescents (14-16 years old), higher leptin levels are found in females than in males $(18.53 \pm 1.41 \mathrm{vs} .6 .33 \pm 1.79$ micrograms/L) where also significant differences were found between obese and non-obese, for leptinemia, triglycerides and HDL cholesterol, with higher values in the obese, for the first two parameters and lower for the third in the adolescents (Martos-Moreno et al., 2013; Martos-Moreno et al., 2013).

Consequently, leptin levels in adolescents are characterized by:

- Be older in women than in men

- Correlating positively with BMI, more in women

- Negatively correlate with HDL

- Present significant differences between adolescents with and without overweight

It has been observed in obese children and adolescents that there are early alterations in the lipid profile, particularly hypertriglyceridemia and decreased HDL-C (Chaila, Fabio, Quiroga, Sánchez de Boeck, Namur, D'urso, \& Bazán, 2012; Cook, Weitzman, Auinger, Nguyen, \& Dietz, 2003).

In contrast, alterations in glycemia were the least common. Even so, impaired fasting glucose and/or impaired glucose tolerance may be early manifestations in childhood obesity and a prelude to diabetes (Chaila et al., 2012).

It has also been shown that leptin may be able to produce insulin resistance in the liver. In a study in obese mice by high-fat diet (animals with resistance to leptin) it was shown that leptin alters the signaling exerted by insulin by 
binding to its receptor in the liver, observing an inhibitory effect on hepatic gluconeogenesis (Morales Clavijo \& Carvajal Garcés, 2010).

An in vitro study with human hepatic cells and hepatocarcinoma cells that expressed the leptin receptor, showed changes in insulin signaling when stimulated with leptin, with decreased tyrosine kinase activity of SRI-1 and decreased inhibition of insulin on gluconeogenesis (Cohen, Novick, \& Rubinstein, 1996; Higashi et al., 2011).

The results confirm that children or adolescents with obesity or overweight presented higher leptin values than subjects with normal weight. Likewise, it has been reported in different publications, that the obese from the neonatal period to old age, have higher serum levels of leptin compared to people of normal weight (Jiménez Guerra \& Martínez Cosme, 2014).

\section{Methods}

Observational study of transversal descriptive type. The population consisted of children and adolescents from the district of Barranquilla, who met the following conditions and who were part of the macroproject "Study of genetic biomarkers: LEP, LEPR, FTO, MC4R, UCP2, ADIPOQ and VDR and their relationship with parameters metabolites as risk factors in a child population resident in the department of Atlántico (North of Colombia)

The inclusion criteria were the following: Age between 5 to 17 years, informed consent signed by the children, informed consent signed by the child's parents, Z-score of the Body Mass Index (BMI)> a - 1DE. (normal:> a $1 \mathrm{DE}$ up to $<2 \mathrm{SD}$ ) overweight: $\geq 2 \mathrm{SD}$ up to $<3$ SD Obesity: $\geq 3 \mathrm{SD}$.

The exclusion criteria were the following: Any individual presenting pathologies or syndromes associated with obesity such as hypothyroidism, Cushing's disease, chromosomopathies or polymalformative syndromes (Prader Willi syndrome, Bardet-Bield syndrome, among others), individuals that are genetically related or related in the study.

To calculate the sample size, the following parameters were taken into account: $95 \%$ confidence level, accuracy of $5 \%$, proportion of $14.5 \%$, which corresponds to the prevalence of the Colombian infantile Colombian population, according to figures from the National Survey of the Male Situation (ENSIN) year 2010 (Ministerio de salud y protección social de Colombia \& Instituto Colombiano de bienestar familiar, 2009). Adjustment of $10 \%$ to the total taking into account the expected proportion of losses. The estimated population of 5 to 15 years in the Department of the Atlantic for the year 2016 was 211,821 according to data from the administrative department of statistics (DANE) and the Mayor of Barranquilla (Departamento Administrativo Nacional de estadística, 2010).

The study protocol was approved by the Committee of EthicsResearch of the Health Area of the Universidad del Norte, in accordance with the Helsinki declaration and Colombian law and written informed consent was obtained from parents.

Taking into account the previous parameters, the calculated population is 179 with a loss adjustment of $10 \%$, for a total of 199 people. However, for this study, 370 patients were taken from the original sample, discarding a group with low weight, which were not part of this study. 130 children corresponded to the study group diagnosed with obesity and 260 corresponded to a control group, without obesity, from this group all members were taken, eliminating only those that were underweight, which left a unified sample of 370 individuals, which were reclassified as a unique database according to their nutritional status in normal, overweight and obese.

The variables used in this study are summarized in Table 1: 
Table 1. Biochemical, sociodemographic and anthropometric study variables

\begin{tabular}{|c|c|}
\hline \multicolumn{2}{|l|}{ Biochemical variables } \\
\hline Variable & Classification - Lower and upper limits \\
\hline Serum glucose levels (mg/dl) & $\begin{array}{l}<70 \mathrm{mg} / \mathrm{dl} \text { (hypoglycemia) }>=70-<105 \text { (normoglicemia) }> \\
105 \mathrm{mg} / \mathrm{dl} \text { (Hyperglycemia) }\end{array}$ \\
\hline Serum levels of total cholesterol (mg/dl) & $\begin{array}{l}\text { Up to } 199 \mathrm{mg} / \mathrm{dl} \text { (Normal) } 200-239 \mathrm{mg} / \mathrm{dl} \text { (moderate) } \\
\text { Greater than } 240 \mathrm{mg} / \mathrm{dl} \text { (elevated) }\end{array}$ \\
\hline Serum levels of HDL cholesterol (mg/dL) & $\begin{array}{l}<35 \mathrm{mg} / \mathrm{dl} \text { (altered). } \\
\geq 35 \mathrm{mg} / \mathrm{dL} \text { (Normal). }\end{array}$ \\
\hline Serum LDL cholesterol levels (mg/dL) & $\begin{array}{l}\text { Formula to calculate LDL: Total cholesterol - (triglycerides) + } \\
\text { HDL } 5 \geq 130 \mathrm{mg} / \mathrm{dl}\end{array}$ \\
\hline Serum levels of VLDL (mg/dL) & Formula to calculate VLDL: Triglycerides $\geq 30 \mathrm{mg} / \mathrm{dl}$ \\
\hline Serum triglyceride levels (mg/dL) & $\geq 150 \mathrm{mg} / \mathrm{dL}$ (altered) \\
\hline Levels of leptin (mg/dL) & Men $(2.05-5.63 \mathrm{ng} / \mathrm{mL})$ Women $(3.7-11.0 \mathrm{ng} / \mathrm{mL})$ \\
\hline \multicolumn{2}{|l|}{ Sociodemographic variables } \\
\hline \multirow{3}{*}{ Age (life cycles) } & 5-9 years (school) \\
\hline & $10-12$ years (pubescent) \\
\hline & $\geq 13$ years (adolescents) \\
\hline Sexo & (Femenino y masculino) \\
\hline \multicolumn{2}{|l|}{ Anthropometric variables } \\
\hline Size & Centimeters \\
\hline Body Mass Index-BMI & Peso $(\mathrm{kg}) /$ altura $\left(\mathrm{M}^{2}\right)$ \\
\hline Z-score of the body mass index BMI & $\begin{array}{l}\text { Normal: }>\text { a }-1 \text { SD to }<2 \text { SD. Overweight: } \geq 2 \text { SD up to }<3 \\
\text { SD. Obesity: } \geq 3 \text { SD. }\end{array}$ \\
\hline
\end{tabular}

Source: Prepared by the authors.

Consent and informed consent was obtained for all obese and non-obese patients. Also, the confidentiality of each of the subjects was guaranteed.

Mac ${ }^{\circledR}$ bookpro hardware was used to process the data. The previously coded data was entered in a sheet of Microsoft $®$ Excel version 2013 and the analysis was performed with the software SPSS $®$ version 20.0.

To control the selection bias, the random selection process was used, which met the inclusion and exclusion criteria, the subjects were sent to assessment for assessment of their nutritional status and according to their results were assigned to one of the groups, so primary sources were used for the study (Daniel \& Hernández, 2005).

To control the information bias, the data that was taken was made by the same researcher with the control of another researcher to verify the measurements taken also using the same laboratory for the sample processing and the taking of random samples against verify results (Daniel \& Hernández, 2005).

To control the confusion biases, participants were taken for the study that were similar, using the stratification in some variables (such as: life cycles, nutritional status) (Daniel \& Hernández, 2005).

According to the type of study and objectives set, the analysis was developed in relation to the nature of the variables, performing a univariate analysis using frequency distribution in absolute and relative measurements in univariate tables for the variables of ratio and interval (age) and frequency distribution for the qualitative variables (nominal and ordinal) in percentages and number of cases, represented in tables, in addition a bivariate analysis was performed with the use of contingency tables for the crossing of the variables. Multivariate analysis was also carried out, taking as control variables (the variables: nutritional status, sex and life cycle) allowing me to analyze the association of the two variables, controlling the effect of the third variable, representing the results in tables. Dispersion measures (Standard Deviation) were used to evaluate and classify the variable nutritional status (BMI Z Score). An inferential, multivariate analysis was performed according to tests of statistical significance. An 
analysis of variance (ANOVA test) was applied using the Bonferroni comparison method, with a value of $\mathrm{p}<0.05$ (Martínez-González, 2014; Kavey, Daniels, Lauer, Atkins, Hayman, \& Taubert, 2003).

\section{Results}

Within the studied population, the highest percentage is between 9-11 years with one (41.1\%), the frequency being lower as age increases with $1.4 \%$ of subjects who are 17 years old. It is found that the average age is 10.1 years, the median is 12 years and 10 years old.

$34.6 \%$ (128 children) belonged to the group of pubescents (from 10 to 13 years old), $41.1 \%$ (152 children) belonged to the group of schoolchildren ( 5 to 9 years) and $24.3 \%$ (90) children) belonged to the group of adolescents ( $>13$ years old)

Approximately one in four individuals has obesity $27.6 \%$ (102 subjects) and one in five overweight $20.3 \%$ ( 75 children), which indicates that $57.9 \%$ (177 subjects) have excess malnutrition.

$45.4 \%$ (168 subjects) had high leptin levels, while 27.3\% (101 subjects) had low leptin levels, showing that $72.7 \%$ ( 269 children) had altered leptin values and only $27.3 \%$ (101 subjects) had normal levels of leptin.

$81.1 \%$ (300 children) had values in normal ranges for glycemia, and $18.9 \%$ (70 subjects) were altered, in which $4.8 \%$ (18 children) had low values of glycemia (hypoglycemia) and 14.1\% (52 children) had high levels of glycemia (Hyperglycemia).

$54.1 \%$ (200 subjects) had values in normal ranges for triglycerides and $45.9 \%$ (170 subjects), had high values of triglycerides.

$83.5 \%$ (309 children) had values in normal ranges for total cholesterol, 14.9\% (55 children) had moderate values of total cholesterol and $1.6 \%$ ( 6 children) had high levels of total cholesterol.

With respect to the behavior of leptin levels according to nutritional status, it is found that in obese and overweight patients they have high leptin levels with $83.3 \%$ and $60 \%$ respectively. While in the group of people of normal weight almost $80 \%$ have low or normal leptin levels

In the overweight and obese male subjects, high leptin levels predominate with $61.5 \%$ and $95.7 \%$ respectively, as in the women in the same nutritional situation, where the percentage reaches $73.2 \%$ in the obese and $59 \%, 2 \%$ in overweight women. An increase in leptin occurs according to the independent nutritional status of the gender.

In children with obesity in all life cycles, high levels of leptin predominate: $74.5 \%$ schoolchildren, $83.9 \%$ pubertal and $100 \%$ adolescents, followed by those who were overweight: $31.8 \%, 70.6 \%$ and $73 \%, 7 \%$ respectively and in smaller percentage those that had a normal weight: $9.6 \%, 15.9 \%$ and $42.6 \%$ respectively. High levels of leptin are found according to the nutritional status, independent of the age group.

When performing an analysis of variances between the variables nutritional status and leptin levels, observing a statistical significance with a $\mathrm{p}$ of, 000 , which rejects the equality of means, indicating that at least one of the groups is different in average to the others, so a post hoc test is used (Bonferroni in this case) that allows us to compare the groups among themselves.

Leptin averages in normal nutritional status and overweight showed significant differences (Sig 0,000$)$ and normal obesity (Sig 0,000), while leptin means between overweight and obese individuals do not present statistically significant differences (Sig: 0.756).

When performing an analysis of variance between the variables leptin levels and glycemia levels, a statistical significance was observed with a $\mathrm{p}$ value of 0.132 , indicating an equality of means, showing a similarity in the response between the groups.

When performing an analysis of variance between the variables leptin levels and triglyceride levels, a statistical significance was observed with a p-value of 0.818 , which indicates an equality of means, showing a similarity in the response between the groups.

An analysis of variance between the variables leptin levels and total cholesterol levels, a statistical significance was observed with a $\mathrm{p}$ of .004 , which rejects the equality of means, indicating that at least one of the groups is different in average to the others.

When performing an analysis of variance between the variables leptin levels and HDL cholesterol levels, a statistical significance was observed with a p of .007, which indicates an equality of means, showing a similarity in the response between the groups.

When performing an analysis of variance between the variables leptin levels and LDL cholesterol levels, a 
statistical significance was observed with a p of 038 , which indicates an equality of means, showing a similarity in the response between the groups.

An analysis of variance between the variables leptin levels and levels of VLDL cholesterol, observing a statistical significance with a p of 690 , which indicates an equality of means, showing a similarity in the response between the groups.

\section{Discussion}

In this study, it was found that there was an increase in leptin levels according to the nutritional status, where it is shown that the amount of leptin released is proportional to the adipose tissue mass, considering adiposity as one of the main determinants of leptin concentrations (Awad, Drescher, Malhotra, \& Quan, 2013; Salud, 2014; Campfield, Smith, Guisez, Devos, \& Burn, 1995), which coincides with that reported in the literature (Salud, 2014).

Since leptin is a hormone that is produced almost exclusively in adipose tissue, hyperplasia and hypertrophy of fat cells, characteristic of overweight and obesity, will increase leptin in an important way, inducing inflammatory dysfunction in this process endothelium and alteration of vascular permeability, which favors the adhesion, migration and accumulation of monocytes and $\mathrm{T}$ lymphocytes in the subendothelial space, which would facilitate vascular damage, favoring the development of the atherosclerotic process and its complications, which determines the appearance of cardiovascular disease and would be the link between obesity and cardiovascular disease (Poveda, Callas, Baracaldo, Castillo, \& Hernández, 2007; Brandão, Lombardi, Nishida, Hauache, \& Vieira, 2003; AL-Suhaimi \& Shehzad, 2013; Falorni et al., 1997).

There is also a clear relationship between obesity and type 2 diabetes, which are characterized by a state of insulin resistance, associated with a significant increase in inflammatory mediators, which has made it possible to postulate leptin as responsible for the relationships between obesity and insulin resistance and between obesity and type 2 diabetes. Leptin and insulin regulate each other. Thus, leptin inhibits the production of insulin in the beta cells of the pancreas, while insulin stimulates the production of leptin in the adipocyte. There is evidence that, in adipocytes, leptin decreases the binding of insulin with its receptors, favoring insulin resistance and becoming a risk factor for type 2 diabetes (M. Palou, Sánchez, Rodríguez, Priego, Picó, \& A. Palou, 2009; Blouet, Liu, Jo, Chua, \& Schwartz, 2012; Coppari \& Bjørbæk, 2012).

Many studies have correlated high levels of leptin with the appearance of various types of cancer, such as the breast where leptin induces activity in aromatase, an enzyme responsible for transforming other steroids into estrogens within breast tissue, finding receptors for leptin in the breast cancer cells, evidence is also available on the relationship between hyperleptinemia and carcinoma of the colon, esophagus and prostate, representing an important line of research in the relationship between leptin and cancer (Li et al., 2016; Jéquier, 2002).

It is advisable to evaluate the usefulness of the measurement of leptin levels, at early ages of life, as a prognostic parameter for obesity in adulthood, as well as a determinant of risk, for diseases such as type 2 diabetes, dyslipidemia and disease. cardiovascular (Camhi, Katzmarzyk, Broyles, Srinivasan, Chen, Bouchard, \& Berenson, 2010; Zhang et al., 2017; Iikuni, Kwan Lam, Lu, Matarese, \& Cava, 2008).

\section{Acknowledgments}

We are very grateful to the families participating in the study "Estudio de los biomarcadores genéticos: LEP, LEPR, FTO, MC4R, UCP2, ADIPOQ y VDR y su relación con parámetros metabólicos como factores de riesgo en una población infantil residente en el departamento del Atlántico".

\section{Competing Interests Statement}

The authors declare that there are no competing or potential conflicts of interest.

\section{References}

AL-Suhaimi, E. A. \& Shehzad, A. (2013). Leptin, resistin and visfatin: the missing link between endocrine metabolic disorders and immunity. Eur. J. Med. Res., 18, 12

Awad, K. M., Drescher, A. A., Malhotra, A. \& Quan, S. F. (2013). Effects of exercise and nutritional intake on sleep architecture in adolescents. Sleep Breath, 17, 117-24.

Blouet, C., Liu, S.-M., Jo, Y.-H., Chua, S. \& Schwartz, G. J. (2012). TXNIP in Agrp neurons regulates adiposity, energy expenditure, and central leptin sensitivity. J. Neurosci., 32, 9870-7.

Borda, M., Tuesca, R. \& Navarro, E. (2011). Métodos cuantitativos Herramientas para la investigación en salud. 
Brandão, C. M. A., Lombardi, M. T., Nishida, S. K., Hauache, O. M. \& Vieira, J. G. H. (2003). Serum leptin concentration during puberty in healthy nonobese adolescents. Brazilian J. Med. Biol. Res., 36, 1293-1296

Camhi, S. M., Katzmarzyk, P. T., Broyles, S., Srinivasan, S. R., Chen, W., Bouchard, C., \& Berenson, G. S. (2010). Predicting Adult Body Mass Index-Specific Metabolic Risk From Childhood. Metabolic syndrome and related disorders, 8(2), 165.

Campfield, L. A., Smith, F. J., Guisez, Y., Devos, R. \& Burn, P. (1995). Recombinant mouse OB protein: evidence for a peripheral signal linking adiposity and central neural networks. Science, 269, 546-9. https://doi.org/10.1126/science.7624778

Chaila, M. Z., Fabio, S., Quiroga, E., Sánchez de Boeck, N., Namur, M., D'urso, M., \& Bazán, M. C. (2012). Prevalencia de Síndrome metabólico en niños y adolescentes según diferentes criterios diagnósticos y su correlación con niveles de leptina y adiponectina. Revista argentina de endocrinología y metabolismo, 49(3), 103-114.

Cohen, B., Novick, D., \& Rubinstein, M. (1996). Modulation of insulin activities by leptin. Science, 274, 1185-8. https://doi.org/10.1126/science.274.5290.1185

Cook, S., Weitzman, M., Auinger, P., Nguyen, M. \& Dietz, W. H. (2003). Prevalence of a Metabolic Syndrome Phenotype in Adolescents. Arch. Pediatr. Adolesc. Med. 157, 821.

Coppari, R. \& Bjørbæk, C. (2012). Leptin revisited: its mechanism of action and potential for treating diabetes. Nat. Rev. Drug Discov., 11, 692-708.

Daniel, W. W., \& Hernández, L. (2005). Bioestadísticabase para el análisis de las ciencias de la salud (No. 574.015195 D3/2005).

Departamento Administrativo Nacional de estadística. (2010). Proyecciones nacionales y departamentales de población 2005 - 2020.

Falorni, A., Bini, V., Molinari, D., Papi, F., Celi, F., Di Stefano, G., ... \& Contessa, G. (1997). Leptin serum levels in normal weight and obese children and adolescents: relationship with age, sex, pubertal development, body mass index and insulin. International journal of obesity, $21(10), 881$.

Gomez, L. (2013). Obesidad infantil en Colombia y América Latina. Un problema de baja prioridad en poblaciones pobres? Retrieved from https://entrenamientofuncionalcarlos.wordpress.com/2013/12/05/obesidad-infantil-en-colombia-y-america-1 atina-un-problema-de-baja-prioridad-en-poblaciones-pobres

Hernández-Arteaga, I., Rosero-Galindo, C. Y., \& Montenegro-Coral, F. A. (2015). Obesidad: una pandemia que afecta a la población infantil del siglo XXI. Curare, 2, 2015.

Higashi, K. et al. (2011). Adipokine ganglioside GM2 activator protein stimulates insulin secretion. FEBS Lett., 585, 2587-91.

Iikuni, N., Kwan Lam, Q., Lu, L., Matarese, G. \& Cava, A. (2008). Leptin and Inflammation. Curr. Immunol. Rev., 4, 70-79.

Irecta Najera, C., \& Álvarez Gordillo, G. (2016). Mecanismos moleculares de la obesidad y el rol de las adipocinas en las enfermedades metabólicas. Rev. Cuba. Investig. Biomédicas, 35.

Jéquier, E. (2002). Leptin signaling, adiposity, and energy balance. Ann. N. Y. Acad. Sci., 967, 379-88.

Jiménez Guerra, F., \& Martínez Cosme, I. (2014). La Prevalencia De Sobrepeso Y Obesidad En Niños Mexicanos De Acuerdo A Tres Criterios Internacionales. Nutr. clínica y dietética Hosp., 34, 2014.

Kavey, R. E. W., Daniels, S. R., Lauer, R. M., Atkins, D. L., Hayman, L. L., \& Taubert, K. (2003). American Heart Association guidelines for primary prevention of atherosclerotic cardiovascular disease beginning in childhood. Circulation, 107(11), 1562-1566.

Li, S., Xiong, X., Harville, E., Zhang, T., Sun, D., Fernandez, C., ... \& Whelton, P. K. (2016). Childhood risk factors and pregnancy-induced hypertension: The bogalusa heart study. American journal of hypertension, 29(10), 1206-1211.

Martínez-González, M. Á. (2014). Bioestadística amigable. (Elsevier, 2014).

Martos-Moreno, G. Á., Barrios, V., Chowen, J. A. \& Argente, J. (2013). Adipokines in Childhood Obesity. Vitamins \& Hormones, 91, 107-142. https://doi.org/10.1016/B978-0-12-407766-9.00006-7 
Martos-Moreno, G. A., Kopchick, J. J., \& Argente, J. (2013). Adipoquinas en el ni-o sano y con obesidad. An. Pediatría 78, 189.e1-189.e15 (2013).

Ministerio de salud y protección social de Colombia \& Instituto Colombiano de bienestar familiar. (2009). Encuesta nacional de la situación nutricional en Colombia 2010.

Morales Clavijo, M., \& Carvajal Garcés, C. F. (2010). Obesidad y resistencia a la leptina. Gaceta Médica Boliviana, 33(1), 63-68.

Organización Mundial de la Salud. (2014). Estadísticas sanitarias mundiales 2014: una mina de información sobre salud pública mundial.

Palou, M., Sánchez, J., Rodríguez, A. M., Priego, T., Picó, C., \& Palou, A. (2009). Induction of NPY/AgRP orexigenic peptide expression in rat hypothalamus is an early event in fasting: relationship with circulating leptin, insulin and glucose. Cellular Physiology and Biochemistry, 23(1-3), 115-124.

Poveda, E., Callas, N. E., Baracaldo, C. M., Castillo, C., \& Hernández, P. (2007). Leptin levels in school age children associated with anthropometric measurements and lipid profiles. Biomedica, 27(4), 505-514.

Salud, O. M. de la. (2014). Datos y cifras sobre obesidad infantil. Retrieved from http://www.who.int/end-childhood-obesity/facts/es/

Sánchez Echenique, M. (2012). Aspectos epidemiológicos de la obesidad infantil. Pediatría Atención Primaria, 14, 9-14. https://doi.org/10.4321/S1139-76322012000200001

Skurk, T., Alberti-Huber, C., Herder, C. \& Hauner, H. (2007). Relationship between Adipocyte Size and Adipokine Expression and Secretion. J. Clin. Endocrinol. Metab., 92, 1023-1033. https://doi.org/10.1210/jc.2006-1055

Zhang, M., Cheng, H., Zhao, X., Hou, D., Yan, Y., Cianflone, K., ... \& Mi, J. (2017). Leptin and leptin-to-adiponectin ratio predict adiposity gain in nonobese children over a six-year period. Childhood Obesity, 13(3), 213-221. https://doi.org/10.1089/chi.2016.0273

Zhang, Y., Zitsman, J. L., Hou, J., Fennoy, I., Guo, K., Feinberg, J., \& Leibel, R. L. (2014). Fat cell size and adipokine expression in relation to gender, depot, and metabolic risk factors in morbidly obese adolescents. Obesity, 22(3), 691-697. https://doi.org/10.1002/oby.20528

\section{Copyrights}

Copyright for this article is retained by the author(s), with first publication rights granted to the journal.

This is an open-access article distributed under the terms and conditions of the Creative Commons Attribution license (http://creativecommons.org/licenses/by/4.0/). 